Document downloaded from:

http://hdl.handle.net/10251/49073

This paper must be cited as:

Caro Forero, LA.; Martí Vargas, JR.; Serna Ros, P. (2013). Time-dependent evolution of strand transfer length in pretensioned prestressed concrete members. Mechanics of TimeDependent Materials. 17(4):501-527. doi:10.1007/s11043-012-9200-2.

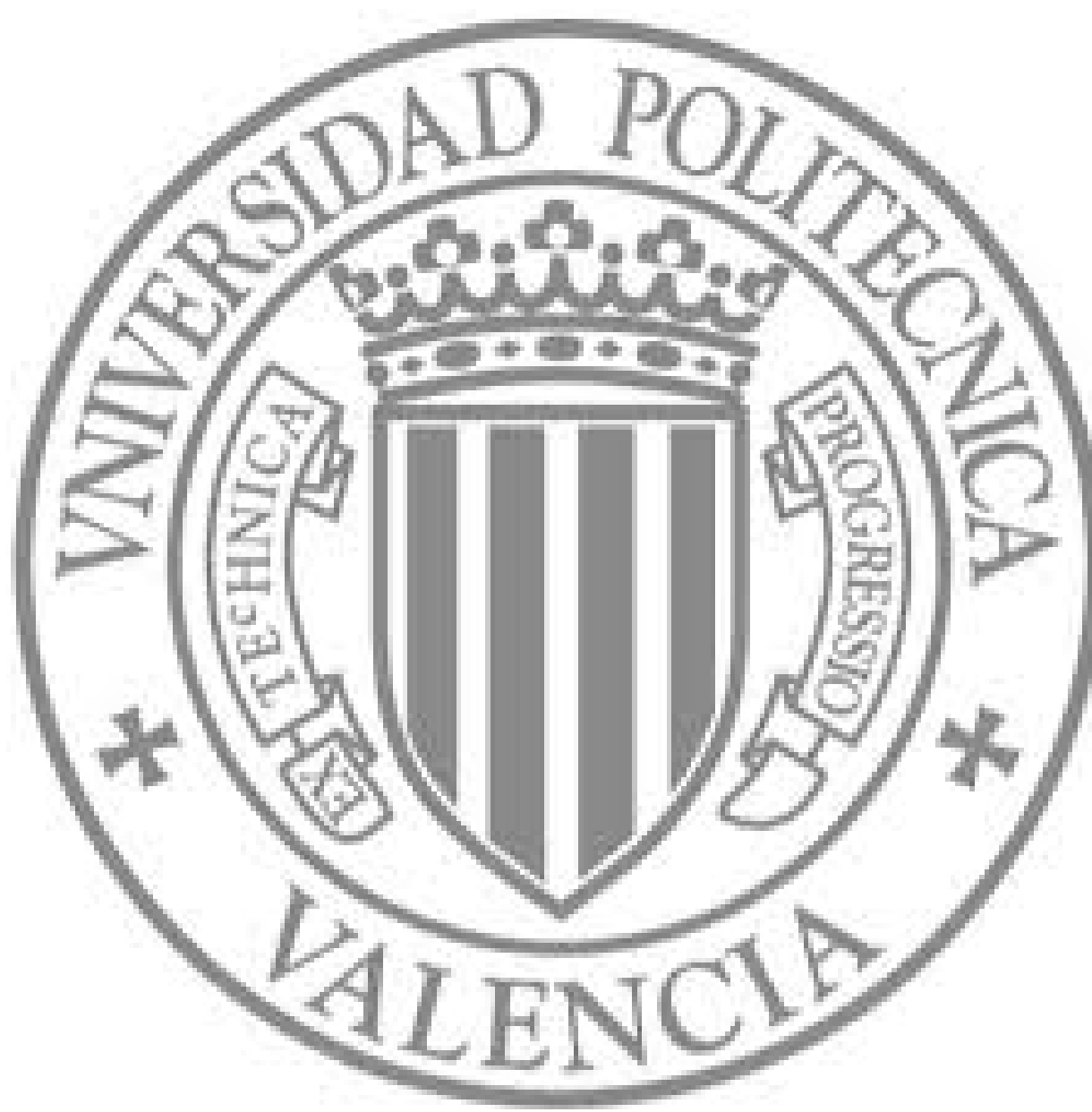

The final publication is available at

http://dx.doi.org/10.1007/s11043-012-9200-2

Copyright Society for Experimental Mechanics (SEM) 


\title{
Time-dependent evolution of strand transfer length in pretensioned prestressed concrete members
}

\author{
L.A. Caro, J.R. Martí-Vargas*, P. Serna \\ Institute of Concrete Science and Technology (ICITECH) \\ Universitat Politècnica de València, 4G, Camino de Vera s/n, 46022, Valencia, \\ Spain \\ e-mail address: \\ licafo@doctor.upv.es; jrmarti@cst.upv.es; pserna@cst.upv.es;
}

*Corresponding author: Tel.: +34 963877007 (ext. 75612); Fax: +34 96 3877569;

e-mail address: jrmarti@cst.upv.es (José R. Martí-Vargas)

\begin{abstract}
For design purposes, it is generally considered that prestressing strand transfer length does not change with time. However, some experimental studies on the effect of time on transfer lengths show contradictory results. In this paper, an experimental research to study transfer length changes over time is presented. A test procedure based on the ECADA testing technique to measure prestressing strand force variation over time in pretensioned prestressed concrete specimens has been set up. With this test method, an experimental program that varies concrete strength, specimen cross-section, age of release, prestress transfer method, and embedment length has been carried out. Both the initial and long-term transfer lengths of 13-mm prestressing steel strands have been measured. The test results show that transfer length variation exists for some prestressing load conditions, resulting in increased transfer length over time. The applied test method based on prestressing strand force measurements has shown more reliable results than procedures based on measuring free end slips and longitudinal strains of concrete. An additional factor for transfer length models is proposed in order to include the time-dependent evolution of strand transfer length in pretensioned prestressed concrete members.
\end{abstract}

Keywords Bond $\cdot$ Concrete $\cdot$ Strand $\cdot$ Prestress $\cdot$ Transfer length · Time 


\section{Introduction}

During the manufacturing process of pretensioned prestressed concrete members, prestressing force is transferred from prestressing strands to concrete by bond at the ends of a member through the prestress transfer operation. According to ACI (2011), transfer length is the distance over which the strand must be bonded to concrete to develop the effective stress $\left(f_{s e}\right)$ in the prestressing strand. Fig. 1 shows an idealization of the prestressing strand stress profile in a large-scale pretensioned prestressed member after the prestress transfer.

Transfer length is a critical parameter in structural design for the calculation of both the flexural and shear capacities of the pretensioned prestressed concrete member, and also for the verification of transverse stresses near their ends (Russell and Burns 1996; Barnes et al. 2003). Several equations to predict transfer length have been proposed by Codes and researchers based on experimental results and theoretical studies. The majority of these equations take a parametric form according to the structure of Eq. (1) (Martí-Vargas et al. 2007a):

$$
L_{t}=\lambda \cdot\left[\chi \cdot\left(\frac{f_{s x}^{n} A_{p}}{\left(k_{1} \pi d_{b}\right) U_{t}}+k_{2}\right)\right]
$$

Where:

$L_{t}=$ transfer length

$\lambda=$ factor to obtain bound values for transfer length

$\chi=$ factor to account for the type of release

$f_{s x}=$ stress in the prestressing strand

$n=$ exponent

$A_{p}=$ cross-sectional area of the prestressing strand

$k_{1}=$ perimeter factor $\left(k_{1}=4 / 3\right.$ for a seven-wire strand, $k_{1}=1$ for a circular crosssection)

$d_{b}=$ nominal diameter of the prestressing strand

$U_{t}=$ average transfer bond stress

$k_{2}=$ adjustment constant

In the ACI-318 Code (ACI 2011) provisions for transfer length (Eq. (2)), $f_{s x}$ is the effective stress $\left(f_{s e}\right)$ in the prestressing strand after allowing for all prestress losses. The ACI transfer length equation was derived from and based on an average transfer bond stress of $2.76 \mathrm{MPa}$ (Tabatabai and Dickson 1993). In addition, several authors (Zia and Mostafa 1977; Shahawy et al. 1992; Mitchell et al. 1993; Deatherage et al. 1994; Buckner 1995; Tadros and Baishya 1996; Mahmoud et al. 1999) consider that using term $f_{s i}$ (the initial effective stress in a prestressing strand just after the prestress transfer, accounting for losses only by the elastic shortening of concrete) in Eq. (1) is more rational for design purposes than $f_{\text {se }}$ by considering that transfer length is established at the release of prestress and that it does not significantly change over time. However, $U_{t}=2.76 \mathrm{MPa}$ is retained in (Shahawy et al. 1992; Deatherage et al. 1994; Buckner 1995; Tadros and Baishya 1996), resulting in longer transfer lengths when $f_{s i}$ is used. 


$$
L_{t}=\frac{f_{s e} d_{b}}{3000}\left(f_{s e} \text { in psi); } L_{t}=\frac{f_{s e} d_{b}}{20.7}\left(f_{s e} \text { in } \mathrm{MPa}\right)\right.
$$

The Model Code 2010 -MC2010- (FIB 2010) transfer length equation (Eq. (3)) takes into account several factors that influence $U_{t}$ : type of release $\left(\alpha_{p 1}\right)$, action effect to be verified $\left(\alpha_{p 2}\right)$, bond situation $\left(\alpha_{p 3}\right)$, tendon type $\left(\eta_{p 1}\right)$, tendon position $\left(\eta_{p 2}\right)$ and concrete tensile strength $\left(f_{c t d i}\right)$. In MC2010, term $f_{s i}$ is considered to calculate transfer length (transmission length), and a lower bound value of transfer length (with $\alpha_{p 2}=0.5$ ) for verification of transverse stress in anchorage zone and an upper bound value of transfer length (with $\alpha_{p 2}=1$ ) for calculation of anchorage length when moment and shear capacity is considered can be distinguished.

$$
L_{t}=\alpha_{p 1} \alpha_{p 2} \alpha_{p 3} \frac{A_{p}}{\pi d_{b}} \frac{f_{s i}}{\eta_{p 1} \eta_{p 2} f_{c t d i}}
$$

In both ACI-318 and MC2010, $\mathrm{n}=1$ and $k_{2}=0$ in Eq. (1). Fig. 2 illustrates these transfer length models at one end zone of a member. In the idealized variation of strand stress along transfer length, the strand stress points from which additional bond length is necessary to increase strand stress when a pretensioned prestressed concrete member is loaded has been illustrated. In all cases, term $f_{s e}$ is used to obtain the aforementioned additional bond length.

In spite of the large number of transfer length equations (Martí-Vargas et al. 2007a; Floyd et al. 2011; Martí-Vargas et al. 2012c) and the different effective stresses considered in the prestressing strand (initial $-f_{s i^{-}}$or long-term $-f_{s e^{-}}$), it is generally considered in the design exercise that the transfer length does not change over time. However, some experimental studies on the effect of time on transfer lengths offer diverging results and it appears that there is an extensive collection of contradictory evidence (Weerasekera 1991, FIB 2010).

The main objective of this experimental research is to analyze transfer length changes over time in pretensioned prestressed concrete members. To achieve this objective, an extensive literature review on the effect of time on transfer length has been firstly done to identify reported tendencies on transfer length changes. This experimental research is not intended to be an extensive study on the factors affecting the time-dependent evolution of prestressing strand transfer length. However with this paper, the authors seek to emphasize that several conditions may exist that result in increased transfer length over time. To this end, an experimental program to determine both the intitial and long-term transfer lengths of 13-mm seven-wire prestressing steel strands in specimens under several test conditions has been carried out by using a modified and improved version of the ECADA test method (Martí-Vargas et al. 2006a). Compared to previous works on this topic, this paper offers an exhaustive bibliography on the subject, it presents the first experimental results obtained by means a testing technique based on the measurement of the prestressing strand force, and it proposes an additional factor for transfer length models to consider the evolution of strand transfer length over time. 


\section{Reported tendencies on transfer length changes}

For prestressing steel strands, three bond mechanisms can be distinguished (FIB 2000): adhesion, friction and mechanical action. Adhesion is destroyed when a very small slip occurs. Then the friction mechanism and the mechanical action are activated and frictional bond stresses are developed, which are caused by radial compressive stresses around the prestressing strand. Several effects contribute to radial compressive stresses (den Uijl 1998, FIB 2000), including long-term effects such as shrinkage of concrete (William et al. 2008) and creep of concrete (Balevicius 2010). Shrinkage of the concrete surrounding the prestressing strand enhances additional radial compressive strength and bond resistance over time, while creep of concrete and prestressing strand relaxation diminish high local stresses and strains and bond stresses (Weerasekera 1991; Barnes et al. 2003; FIB 2010). Moreover, the aforementioned effects may be counteracted by increased concrete strength over time (FIB 2010).

Several research studies available in the scientific literature have reported experimental data of transfer length changes with time. The majority of the authors usually apply experimental techniques based on the analysis of the strain profiles on the concrete specimen surface after detensioning (RILEM 1979; Russell and Burns 1996) to determine transfer length and time-dependent evolution. Furthermore, the prestressing strand slips based on Guyon's theory at the ends of the member are frequently analyzed (Guyon 1953; Oh and Kim 2000; Martí-Vargas et al. 2007b).

Table 1 summarizes the main conclusions reported in an extensive collection of papers. Accordingly, different time intervals have been considered (from 7 days to 2.5 years), as well as prestressing reinforcement types (wires, strands, Dyform compacted- FRP tendons) and several nominal diameters (2.0-15.2 mm). Transfer length increases (up to 190\% of the initial value) have been reported by several authors. However, transfer length decreases have also been reported, and no changes in transfer length with time have been observed in some cases. Besides, several authors have stated that transfer length increases do not seem to occur in any orderly fashion or follow any particular pattern and, in some cases, the results differed significantly for the two ends of the same specimen.

\section{Experimental technique}

A recent experimental methodology, the ECADA test method (Martí-Vargas et al. 2006a), based on the measurement of the force supported by prestressing strands, has been conceived, and it has been applied to determine transfer length (MartíVargas et al. 2006b; 2012a). ECADA is the Spanish acronym for "Ensayo para Caracterizar la Adherencia mediante Destesado y Arrancamiento": which, in English, is “Test to Characterize Bond by Release and Pull-out”.

As a revised and improved version of the original ECADA test method, the ECADA+ test method (Martí-Vargas et al. 2012b) has been developed to study transfer length changes over time by determining both the initial and the longterm transfer lengths of prestressing reinforcement in pretensioned prestressed concrete members. In this work, the ECADA+ test method has been used. 
The ECADA+ test method is based on the instantaneous and time-related analysis of the prestressing strand force in series of pretensioned prestressed concrete specimens with different embedment lengths. To this end, several specimens, whose embedment length varies only, are performed and tested under the same conditions using pretensioning frames as shown in Fig. 3.

To facilitate tensioning, provisional anchorage and detensioning of prestressing strands, a hollow hydraulic actuator with an end-adjustable anchorage device is required. This actuator is placed on the active end of the pretensioning frame. A mechanical system to facilitate the anchorage-measurement-access of the prestressing strand (the AMA system) is placed on the passive end of the pretensioning frame. The AMA system is made up by the sleeve, the end frame plate, the anchorage plate, and the support separators placed between both plates (see Fig. 3). The AMA system also makes it possible to simulate the sectional rigidity of the concrete specimen and to prevent the influence of the confinement caused by the end frame plate by using a sleeve.

\subsection{Test procedure}

A complete test method approach of ECADA+ has been included in Martí-Vargas et al. (2012b). The following subsections summarize the step-by-step test procedure.

\subsubsection{Specimen preparation and fabrication}

- Mounting the equipment test setup as Fig. 3 depicts.

- Placing the strand on the pretensioning frame.

- Both anchorage devices are placed on the ends of the strand.

- Strand tensioning using the hydraulic actuator (Fig. 4a).

- Provisional strand anchorage by the end-adjustable anchorage device which mechanically blocks the hydraulic actuator by unscrewing until it comes into contact with their core (Fig. 4b).

- Specimen concreting into an integrated mould mounted within the pretensioning frame, around the prestressing strand (Fig. 4c).

- The concrete remains in its mould during a given time to achieve the desired mechanical properties prior to testing.

- Demounting the mould from the pretensioning frame.

\subsubsection{Prestress transfer release}

- Releasing the provisional anchorage: the hydraulic actuator recovers the prestressing strand force, and the end-adjustable anchorage device is relieved (Fig. 4d).

- Detensioning: the hydraulic actuator is unloaded, and the movement of the prestressing strand toward the passive end is produced (Fig. 4e); when the strand has been completely released, the prestressed concrete specimen is supported by acting on the AMA system. 
- Stabilization: period established to guarantee the measurement of the prestressing strand force which depends on the strain compatibility with the concrete specimen.

- Measuring the prestressing strand force achieved $\left(\mathrm{P}_{\mathrm{I}}\right)$ in the AMA system.

\subsubsection{Initial analysis}

- Estimating the AMA system response for the actual test conditions; the theoretical value $\mathrm{P}_{\mathrm{IE}}$ (initial effective prestressing force in the strand from the designed AMA system components) is obtained.

- Comparing the measured $\mathrm{P}_{\mathrm{I}}$ value with $\mathrm{P}_{\mathrm{IE}}$; two possible test results may be presented:

a) if $\mathrm{P}_{\mathrm{I}}<\mathrm{P}_{\mathrm{IE}}$, the test finishes and the tested specimen may be removed.

b) if $\mathrm{P}_{\mathrm{I}} \approx \mathrm{P}_{\mathrm{IE}}$, the test continues.

\subsubsection{Specimen storage}

- Demounting the pretensioned prestressed concrete specimen joined to the AMA system from the pretensioning frame (Fig. 4f).

- Maintaining the demounted test specimen under controlled storage conditions.

- Subsequently measuring the prestressing strand force at a given time is done periodically.

\subsection{Fixed test parameters}

Specimens have been prestressed by means of a concentrically located single strand at a prestress level before releasing $75 \%$ of the nominal ultimate strand strength. All the specimens have been subjected to the same consolidation and curing conditions.

The prestress transfer release time has been specified for each series of specimens. A standard release has been gradually performed at a controlled speed of 0.80 $\mathrm{kN} / \mathrm{s}$. However, several specimens have been released at the maximum possible speed by the free action of the hydraulic actuator $(100 \mathrm{kN} / \mathrm{s})$. A stabilization period of 2 hours from the release has been established for the initial analysis.

The specimens for the long-term study have been stored inside a chamber where temperature and humidity were controlled: temperature at $20-22^{\circ} \mathrm{C}$; relative humidity at $50-60 \%$.

\subsection{Instrumentation devices}

In accordance with the ECADA+ test method, the strictly necessary instrumentation devices are a hydraulic pressure sensor to control the tensioning and detensioning operations, and a hollow force transducer included in the AMA system to measure prestressing strand force at all times during the test (tensioning, provisional anchorage, detensioning, and analysis with time). 
Additionally, this instrumentation may be complemented with optional devices to measure the prestressing strand end slip at the free end of the specimen and strain gauges to determine the longitudinal concrete surface strain profile.

In this work, the prestressing strand end slip has been measured by displacement transducers (in the test stages in the pretensioning frame) and by means of analogic micrometers (in the storage stage), while demountable mechanical gauges (DEMEC points) have been used to measure the longitudinal concrete surface strain at the prestressing strand level. In all cases, internal measuring devices have not been used in test specimens in order to avoid any distortion of the strand-concrete bond phenomenon.

The instrumentation devices used in this work have been: pressure sensor Druck PDCR 4000350 bar (accuracy $\pm 0.08 \%$ ), force transducer HBM C6A $500 \mathrm{kN}$ (sensitivity $2 \mathrm{mV} / \mathrm{V}$, accuracy class 0.5 ), linear displacement sensor Penny Giles SLS190/50/2K/L/50/01 (typical linearity 0.15\%), micrometers Käfer 0-5 mm Ø58 (accuracy $\pm 1 \mu \mathrm{m}$ ), and mechanical gauges Mayes Instruments $100 \mathrm{~mm}$ base length (accuracy $\pm 5 \mu \mathrm{m}$ ).

\subsection{Initial transfer length determination}

With the ECADA+ test method, transfer length is obtained from a series of specimens with different embedment lengths. The obtained prestressing force $\mathrm{P}_{\mathrm{I}}$ values are ordered according to the specimen embedment length, and a bilinear tendency with an ascendent initial branch and a practically horizontal branch corresponding to the initial effective prestressing force $\mathrm{P}_{\mathrm{IE}}$ can be observed. The initial transfer length corresponds to the specimen embedment length which marks the beginning of the horizontal branch; that is, it corresponds to the shorter specimen embedment length which presents a $P_{I}$ value equal to the initial effective prestressing force $\mathrm{P}_{\mathrm{IE}}$ (Fig. 5). The resolution during transfer length determination depends on the sequence of the lengths of the specimens tested.

\subsection{Long-term transfer length determination}

Specimens with $\mathrm{P}_{\mathrm{I}} \approx \mathrm{P}_{\mathrm{IE}}$ are stored inside a chamber under controlled conservation conditions. Then the prestressing strand force at certain time $j\left(\mathrm{P}_{\mathrm{J}}\right)$ in the AMA system is periodically measured (every day the first week, every week during two months, and after monthly). With time, the prestressing strand force value lowers due to the time-dependent effects. For each time $j$, the subsequent $\mathrm{P}_{\mathrm{J}}$ readings are arranged according to the specimen embedment length, and two possible test results may be presented:

a) if all the test specimens have similar $P_{J}$ values (Fig. 5, case (a)), no changes in transfer length exists (the actual effective prestressing force $\mathrm{P}_{\mathrm{JE}}$ is achieved in all the specimens); and

b) if one or more specimens show a smaller $P_{J}$ value compared with the remaining ones in the series, then transfer length variation exists: the long-term transfer length at time $j$ corresponds to the shorter specimen embedment length which marks the beginning of the horizontal branch; that is, it corresponds to the shorter specimen embedment which presents a $P_{J}$ value equal to the actual effective prestressing force $\mathrm{P}_{\mathrm{JE}}$ (Fig. 5, case (b)). 


\section{Experimental program}

This experimental work intends to emphasize that several conditions may exist which result in increased transfer length over time. To this end, an experimental program that varies concrete strength, cross-section, age of release, prestress transfer method, and embedment length has been carried out to determine both the initial and long-term transfer lengths of the 13-mm seven-wire prestressing steel strands.

The series of specimens have been performed in a total of six pretensioning frames. Several demountable AMA systems were available for this work, and the size of the controlled storage chamber was considered to carry out the test program.

\subsection{Materials}

Three different concrete mixes applicable for the precast prestressed concrete members industry with different compressive strengths at the time of testing $f^{\prime}{ }_{c i}$ ranging from 24 to $58 \mathrm{MPa}$ have been tested. For all the concretes, the components were: cement CEM I 52.5 R (CEN 2000), crushed limestone aggregate (7-12 $\mathrm{mm})$, washed rolled limestone sand $(0-4 \mathrm{~mm})$, and a superplasticizer additive. The mix design and concrete properties of the tested concretes are shown in Table 2.

The prestressing strand is a low-relaxation seven-wire strand specificied as UNE 36094:97 Y 1860 S7 13.0 (AENOR 1997) with a guaranteed ultimate strength of $1860 \mathrm{MPa}$. The main characteristics have been adopted from the manufacturer: diameter of $13 \mathrm{~mm}$, a cross-sectional area of $100 \mathrm{~mm}^{2}$, ultimate strength of 200.3 $\mathrm{kN}$, yield stress at $0.2 \% 189.9 \mathrm{kN}$, and modulus of elasticity of $203.35 \mathrm{GPa}$. The prestressing strand has been used under the as-received condition. Strands were rust- and lubricant-free, without any special treatment.

\subsection{Program}

In addition to the above-detailed fixed test parameters (see Section 3.2), the test program includes several test conditions. Three different specimen cross-sections have been used: $100 \times 100 \mathrm{~mm}^{2}, 80 \times 80 \mathrm{~mm}^{2}$, and $60 \times 60 \mathrm{~mm}^{2}$, and they have been combined with the three concretes. Besides, several prestress transfer release ages have been established.

For some of the test program combinations, complete series of specimens with different embedment length have been made. According to the ECADA+ test method, embedment length sequences with a resolution of $50 \mathrm{~mm}$ have been used in this work to determine the initial transfer length and to select the specimens with an embedment length equal to or longer than the initial transfer length to store several specimens in the controlled chamber. 
In three cases for concrete type A, long specimens have been tested to analyze the effect of the prestress transfer method: gradual action when a controlled detensioning speed of $0.80 \mathrm{kN} / \mathrm{s}$ has been applied, and free action when the maximum possible speed by the free action of the hydraulic actuator has been applied, have been released.

The designation of a specimen is: M-D-T-L-F, Where:

$\mathrm{M}$ is the concrete mix type $(\mathrm{A}, \mathrm{B}$, or $\mathrm{C})$

$\mathrm{D}$ is the dimension in $\mathrm{mm}$ of the specimen cross-section $(100,80$ or $60 \mathrm{~mm})$

$\mathrm{T}$ is the age in hours (h) at the prestress transfer release $(6,12,24$ or $48 \mathrm{~h}$ )

$\mathrm{L}$ is the embedment length (in mm) or "LS" for long embedment length (1350 $\mathrm{mm}$ )

$\mathrm{F}$ is the added identifier " $\mathrm{F}$ " when the prestress transfer method is of a free action kind

Designation for a complete series includes only the parameters detailing M-D-T.

Table 3 summarizes the test program established. It has not been possible to test all the combinations because of the size of the controlled storage chamber. As observed in Table 3, specimens with a long embedment length $(1350 \mathrm{~mm})$ have been included in all the tested combinations for different purposes: to form part of a series, to supplement it, and to obtain some test results under test conditions for which no complete series has been made. These long specimens (LS) have been additionally instrumented with DEMEC points to determine the longitudinal concrete surface strain profile at the prestressing strand level. Fig. 6 offers a general view of some of the specimens stored.

\section{Test results and discussion}

For the established program test conditions, both the initial and long-term transfer lengths after 12 months have been measured by the ECADA+ test method. Besides, the prestressing strand end slip and the longitudinal concrete surface strain have been measured in some cases.

\subsection{Initial transfer length}

For each complete series, the initial transfer length has been determined in accordance with the criterion presented (see Section 3.4). By way of example, Fig. 7 provides the results of transferred prestressing forces versus the embedment lengths for the A-80-24 series. All the test specimens with embedment lengths equal to or longer than $500 \mathrm{~mm}$ present identical $\mathrm{P}_{\mathrm{I}}$ values and, therefore, equal the initial effective prestressing force $\mathrm{P}_{\mathrm{IE}}$. In contrast, all the test specimens with embedment lengths shorter than $500 \mathrm{~mm}$ present smaller $\mathrm{P}_{\mathrm{I}}$ values. Thus with the resolution of the lengths used, the initial transfer length determined by the ECADA+ test method can be affirmed as $500 \mathrm{~mm}$ in this case. 


\subsection{Time-dependent analysis and long-term transfer length}

For each complete series, the long-term transfer length has been determined in accordance with the criterion presented (see Section 3.5). Previously for each stored test specimen, the subsequent set of prestressing strand force $\left(\mathrm{P}_{\mathrm{J}}\right)$ readings has been taken periodically after the prestress transfer for up to 12 months, which have been arranged according to time, as illustrated in Fig. 8, for the A-80-24 series test conditions.

As Fig. 8 depicts, the prestressing force readings present similar tendencies and values for all the specimens, except for the specimen with a shorter embedment length (A-80-24-500). This specimen exhibits a different behavior: two months after the prestress transfer release, a greater prestressing force loss was registered, and the prestressing strand force strongly diminished with time if compared to the remaining test specimens. Consequently, transfer length variation exists in this case, which can be used to identify the specimen that marks the new transfer length value (the next in the embedment length sequence tested, specimen A-8024-550) and the time at which this transfer length change took place (two months). In a general case, this process may be done with other specimens by following the embedment length sequence.

According to the ECADA+ test method, and for both the initial and the 12-month prestressing strand force profiles, Fig. 9a shows the transfer length test results for the A-100-24 series test conditions (without transfer length change over time), whereas Fig. 9b depicts the transfer length test results for the A-80-24 series test conditions (with transfer length change over time). In this case, the long-term transfer length at 12 months corresponds to the shorter specimen embedment length which marks the beginning of the horizontal branch. Therefore with the resolution of the lengths used, it can be affirmed that a transfer length variation of $50 \mathrm{~mm}$ exists for the A-80-24 series test conditions, which implies a $10 \%$ increase in the initial transfer length.

Table 4 summarizes the test results obtained for all the complete series over a 12month period. As seen, the test method is capable of performing the timedependent evolution of prestressing strand transfer length in pretensioned prestressed concrete members, by transfer length determination at detensioning and in the storage stage to analyze the possible transfer length variation. The following trends can be observed in Table 4:

a) both the initial and long-term transfer lengths are shorter when the concrete compressive strength increases; then the series which differs only in terms of concrete type shows a shorter transfer length when the concrete used is type A than when it is type $\mathrm{B}$, and higher transfer length values are found per concrete type C (A-100-24/B-100-24/C-100-24; B-100-48/C-100-48 -only for long-term-; A-80-24/B-80-24; B-80-48/C-80-48);

b) the initial transfer length can be shorter when the prestress transfer age increases (A-100-24 versus A-100-12; $\mathrm{B}-80-48$ versus $\mathrm{B}-80-24$; and $\mathrm{C}-100-48$ versus C-100-24);

c) for specimens with a longer cross-section $\left(100 \mathrm{x} 100 \mathrm{~mm}^{2}\right)$, transfer length variation exists for the early prestress transfer age (A-100-12 versus A-100-24), and also for the late prestress transfer (C-100-48);

d) for specimens with cross-section of $80 \times 80 \mathrm{~mm}^{2}$, transfer length variation exists in practically all the cases tested (A-80-24; B-80-24; and B-80-48); and 
e) for concrete type $\mathrm{C}$, there is transfer length variation for the $\mathrm{C}-100-48$ series (a late prestress transfer and a longer cross-section), and there are no transfer length variation for the early prestress transfer (C-100-24 versus C-100-48) and the shorter cross-section (C-80-48 versus C-100-48): this can be explained by the transfer length values being initially higher for C-100-24 and C-80-48 (800 mm) and by them being maintained over time, whereas the initial transfer length for C$100-48$ is shorter $(650 \mathrm{~mm})$ and increases to $100 \mathrm{~mm}$ over the 12 -month period.

For those cases showing evolution of the transfer length over time, Fig. 10 illustrates the influence of the concrete stress level of the specimens in the series on the corresponding change of the transfer length $\left(\Delta L_{t}\right)$ computed according to Eq. (4). The concrete stress level has been obtained by dividing the initial effective prestressing force transferred between the specimen's cross-section and the concrete compressive strength at the prestress transfer. As observed, the change of the transfer length over time increases when the concrete stress level increases.

$$
\Delta L_{t}=\frac{L_{t, \text { long-term }}-L_{t, \text { initial }}}{L_{t, \text { initial }}} \cdot 100
$$

\subsection{Comparison of the test results with the strand end slips method}

For each stored test specimen, the prestressing strand end slips have been measured and the subsequent readings at given time $j$ have been arranged according to time, as illustrated by Fig. 11 for the A-80-24 series test conditions. As observed, the strand end slips present similar tendencies and values for all the specimens, except for the specimen with a shorter embedment length (A-80-24500). This specimen exhibits a different behavior: two months after the prestress transfer release, a greater slip was registered, and the strand end slip strongly increased with time compared to the remaining test specimens. Consequently, and in agreement with the registered response through the prestressing force measurements, transfer length variation exists in this case. In a general case, however, this process may be done with other specimens by following the embedment length sequence.

Guyon (Guyon 1953) proposed the following expression to predict transfer length:

$$
L_{t}=\alpha \frac{\delta E_{p}}{\sigma_{p 0}}
$$

where $\mathrm{L}_{\mathrm{t}}$ is the transfer length, $\delta$ is the strand end slip at the prestress transfer, $\mathrm{E}_{\mathrm{p}}$ is the modulus of elasticity of the prestressing strand, $\sigma_{\mathrm{p} 0}$ is the prestressing strand stress immediately before release, and the $\alpha$ coefficient represents the shape factor of the bond stress distribution along the transfer zone ( $\alpha=2$ for uniform bond stress distribution; $\alpha=3$ for linear descending bond stress distribution).

This expression has been applied to the free end slips registered in specimens with embedment lengths longer than the transfer length according to the ECADA+ test method. Fig. 12 shows the transfer lengths computed according to Guyon's 
expression for the A-100-24 (Fig. 12a) and A-80-24 (Fig. 12b) series at the prestress transfer and after 12 months by applying the $\alpha=2$ and $\alpha=3$ coefficients. As observed, the variability of the results obtained from the strand end slips was considerable, with predictions giving transfer length values that have practically doubled within the same combination (for example, initial transfer length values ranging from 282 to $504 \mathrm{~mm}$ for A-80-24 with $\alpha=2$ ). Both the initial and longterm transfer lengths have been obtained by averaging the corresponding values (only the specimen A-80-24-500 values at 12 months have been excluded to compute the average 12-month transfer length).

As the strand end slip values increase with time, transfer length increase exists. For the A-100-24 series, the transfer length change has been obtained from the strand end slips (286-258 $=28 \mathrm{~mm}$ when $\alpha=2$ and 429-387 $=42 \mathrm{~mm}$ when $\alpha=$ 3 ), which were smaller than the resolution used for the specimen embedment lengths $(50 \mathrm{~mm})$; these transfer length change have not been measured by the ECADA+ test method. However for the A-80-24 series, the transfer length change obtained from the strand end slip (435-389 = 46 mm when $\alpha=2$ and 652-583 = $69 \mathrm{~mm}$ when $\alpha=3$ ) was in the order of or greater (as a function of the applied $\alpha$ coefficient) than $50 \mathrm{~mm}$, in accordance with Fig. 11 and the ECADA+ test results for the A-80-24 series (Fig. 9b), while the transfer length change was $50 \mathrm{~mm}$. On the other hand, the 12-month transfer length change obtained from the strand end slips of the A-80-24-500 specimen was considerably greater (638 mm when $\alpha=2$ and $957 \mathrm{~mm}$ when $\alpha=3$ ). For this specimen, the transfer length change would be 638-282 $=356 \mathrm{~mm}$ when $\alpha=2$ and 957-424 $=533 \mathrm{~mm}$ when $\alpha=3$, which is much greater than $50 \mathrm{~mm}$.

Although the existence of transfer length change can be detected from strand end slips measurements, Guyon's expression is not applicable for these cases (a shorter embedment length than the actual transfer length), and it is not possible to quantify the long-term transfer length. Therefore, the strand end slip method is not viable to analyze transfer length change over time given this fact, the unknown value for the $\alpha$ coefficient to be applied, and the considerable variability of the results obtained from the strand end slips. Consequently, the application of the ECADA+ method based on the measurement of forces for transfer length determination has provided more reliable results than those obtained by applying the method based on strand end slip measurements.

\subsection{Comparison of the test results with the longitudinal concrete strains method}

The results obtained from the complete series with the ECADA+ test method have been compared with the results based on the longitudinal concrete surface strain profile from long specimens. This method consists in determining the strains on the surface of the concrete specimen after the release, based on the distance to the end. These strains follow a law similar to that of the strand stress shown in Fig. 1.

Fig. 13 illustrates the test results of both the long specimens: A-100-24-1350 (Fig. 13a) and A-80-24-1350 (Fig. 13b). The transfer length obtained by means of the ECADA+ test method is also indicated: $450 \mathrm{~mm}$ (initial and long-term) for specimen A-100-24-1350, and $500 \mathrm{~mm}$ (initial) and $550 \mathrm{~mm}$ (long-term) for specimen A-80-24-1350. Fig. 13a reveals that, given the slope of the first part of 
the curve, it may be assumed that the plateau begins at $400 \mathrm{~mm}$ after the detensioning for specimen A-100-24-1350; another interpretation could be that the plateau begins between 400 to $600 \mathrm{~mm}$ after 12 months. Also in Fig. 13b for specimen A-80-24-1350, one interpretation could be that the plateau begins between 350 to $500 \mathrm{~mm}$ after detensioning, and that the transfer length change does not appear after 12 months, whereas at this time, a clear beginning of the plateau is seen for $450-500 \mathrm{~mm}$ (but not for $550 \mathrm{~mm}$ as illustrated by Figs. 8, 9b and 11).

Table 5 includes both the initial and the long-term transfer lengths after 12 months for all the long specimens additionally instrumented with DEMEC points. Transfer lengths have been determined directly from the concrete strain profiles. When a range of values has been identified for the beginning of the strains plateau, the non selected bound value of this range has been specified in parentheses. As observed, given the difficulty of detecting the beginning of the strains plateau, the method based on the longitudinal concrete surface strain profile enables us to determine the initial and long-term transfer lengths less accurately than the ECADA+ method.

Finally, the long specimens tested to analyze the effect of the prestress transfer method did not show any pattern relating to both the initial and long-term transfer lengths. Only for those specimens with an early prestress transfer (A-100-12) have longer transfer lengths been obtained when the maximum possible speed by the hydraulic actuator's free action has been released. However, all the specimens released by means of this free action have presented transfer length evolution over time.

\section{Proposed additional factor for transfer length models}

From the test results obtained with this experimental work and with the increases of transfer length over time reported in the literature, an additional factor for the transfer length models is proposed to include the changes of strand transfer length over time in pretensioned prestressed concrete members. Based on the simplified model according to Eq. (1), the following is proposed:

$$
L_{t}=\xi \cdot \lambda \cdot\left[\chi \cdot\left(\frac{f_{s x}^{n} A_{p}}{\left(k_{1} \pi d_{b}\right) U_{t}}+k_{2}\right)\right]
$$

where $\xi$ is the new factor accounting for transfer length changes with time. Fig. 14 shows the extended transfer length model.

There are not enough experimental data from this work to derive $\xi$ in terms of time, and $\xi=1$ (no change in transfer length) in some cases. Moreover, contradictory results on changes of transfer length over time have been reported in the scientific literature (see Table 1): transfer length increases, no changes in transfer length, transfer length decreases, and no transfer length changes pattern. Therefore, a factor $\xi=1.2$ must be considered for the test results obtained from 
this work. However, values higher than $\xi=1.6$-average- ( $\xi=2.9$-maximum-) have been experimentally obtained from other authors, as shown in Table 1 (the case of Ramirez and Russell 2008). Since the $\xi$ factor value has been established from very few test specimens, an ambitious experimental program should be carried out to extend this experimental database. Any further work done on the transfer length evolution over time and its analysis to establish the $\xi$ factor value to majority of the pretensioned prestressed concrete structural members will be acknowledged.

\section{Conclusions}

The following conclusions may be drawn from this experimental work:

- Several research studies available in the scientific literature have reported experimental transfer length changes data with time. An exhaustive bibliography on the subject has been analyzed. Different time intervals have been considered in these studies, as well as prestressing reinforcement type and diameter. Contradictory results on transfer length changes with time have been reported: transfer length increases, no changes in transfer length, transfer length decreases, and no transfer length changes pattern.

- An experimental program to both analyze transfer length changes and determine the initial and long-term transfer lengths after 12 months of the 13$\mathrm{mm}$ prestressing strand in pretensioned prestressed concrete members has been carried out. The recently conceived ECADA+ test method based on the prestressing strand force measurement has been applied. This test method allows the study of those parameters affecting the bonding in the transfer length evolution over time, such as concrete type, prestressing reinforcement type, specimen cross-section, level of prestress, release age and method, and storage conditions.

- Transfer length change over time has been observed in some cases under several prestressing load conditions, resulting in increased transfer length with time, such as an early prestress transfer and shorter specimen cross-sections.

- When transfer length change occurs, the percentages of variation of transfer length relating to the initial transfer length are higher when the concrete stress level due to the effective prestressing force is higher.

- Transfer length change can be detected from measuring the strand end slips. However, Guyon's expression is not applicable for these cases (the embedment length is shorter than the actual transfer length) and it is not possible to quantify the long-term transfer length. The strand end slip method is not viable to analyze transfer length change over time given this fact, the unknown value for the $\alpha$ coefficient to be applied, and the considerable variability of the results obtained.

- The method based on the longitudinal concrete surface strain profile enables us to determine transfer length less accurately than the ECADA+ method due to the difficulty of detecting the beginning of the strains plateau.

- All the specimens released by means of the hydraulic actuator's free action have presented transfer length evolution over time. However, no pattern relating to both the initial and long-term transfer lengths values has been observed. 
- Finally, a new additional factor for the transfer length models is proposed to consider the time-dependent evolution of the strand transfer length in pretensioned prestressed concrete members.

Acknowledgments Funding for this experimental research work has been provided by the Spanish Ministry of Education and Science and ERDF (Projects BIA2006-05521 and BIA200912722). Tests have been conducted at the Institute of Concrete Science and Technology (ICITECH), at the Universitat Politècnica de València (Spain).

\section{References}

ACI: ACI 318-11 Building Code Requirements for Reinforced Concrete. ACI Committee 318, American Concrete Institute, Farmington Hills, MI (2011)

AENOR: UNE 36094:1997 Alambres y cordones de acero para armaduras de hormigón pretensado. Asociación Española de Normalización, Madrid (1997)

Balevicius, R.: An average stress strain approach to creep analysis of RC uncracked elements. Mech. Time-Depend. Mater. 14, 69-89 (2010)

Barnes, R.W., Grove, J.W., Burns, N.H.: Experimental assessment of factors affecting transfer length. ACI Struct. J. 100(6), 740-748 (2003)

Base, G.D.: Some tests on the effect of time on transmission length in pretensioned concrete. Mag. Concr. Res. 4, 73-82 (1957)

Base, G.D.: An Investigation of Transmission Length in Pretensioned Concrete. Cement and Concrete Association, Research Report $n^{\circ} 5$ (1958)

Bruce, R.N., Russell, H.G., Roller, J.J., Martin, B.T.: Feasibility evaluation of utilizing highstrength concrete in design and construction of highway bridge structures. Louisiana Transportation Research Center. Report n ${ }^{\circ}$ FHWA/LA-94-282. Baton Rouge, LA (1994)

Buckner, C.D.: A review of strand development length for pretensioned concrete members. PCI J. 40(2), 84-105 (1995)

CEN: European standard EN 197-1:2000: Cement. Part 1: Compositions, specifications and conformity criteria for common cements. Comité Européen de Normalisation, Brussels (2000)

Cousins, Th.E., Johnston, D.W., Zia, P.: Transfer length of epoxy-coated prestressing strand. ACI Mat. J. 87(3), 193-203 (1990)

Deatherage, J.H., Burdette, E., Chew, Ch.K.: Development length and lateral spacing requirements of prestressing strand for prestressed concrete bridge girders. PCI J. 39(1), 70-83 (1994)

den Uijl, J.A.: Bond modelling of prestressing strand. In: Bond and development of reinforcement (SP 180-7), pp. 145-169. ACI International, Farmington Hills, MI (1998)

Dorsten, V., Hunt, F.F., Preston, H.K.: Epoxy coated seven-wire strand for prestressed concrete. PCI J. 29(4), 100-109 (1984)

Evans, R.H.: Research and developments in pre-stressing. P. I. Civil Eng. 35, 231-261 (1951)

Evans, R.H., Robinson, W.R.: Bond stresses in prestressed concrete from X-ray photographs. P. I. Civil Eng. 6(14), 212-235 (1955)

FIB: MODEL CODE 2010 (First complete draft). FIB Bulletin nº55. International Federation for Structural Concrete. Lausanne (2010)

Floyd, R.W., Howland, M.B., Hale, W.M.: Evaluation of strand bond equations for prestressed members cast with self-consolidating concrete. Eng Struct. 33, 2879-2887 (2011)

Girgis, A.F., Tuan, Ch.Y.: Bond strength and transfer length of pretensioned bridge girders cast with self-consolidating concrete. PCI J. 50(6), 72-87 (2005)

Grace N.F.: Transfer length of CFRP/CFCC strands for double-T girders. PCI J. 45(5), 110-126 (2000)

Guyon Y.: Béton précontrainte. Étude théorique et experiméntale. Eyrolles, Paris (1953)

Holmberg, A., Lindgren, S.: Anchorage and prestress transmission. National Swedish Building Research, Document D1/1970 (1970)

Issa, M.A., Sen, R., Amer, A.: Comparative study of transfer length in fiberglass and steel pretensioned concrete members. PCI J. 38(6), 52-63 (1993)

Kaar, P.H., LaFraugh, R.W., Mass, M.A.: Influence of concrete strength on strand transfer length. PCI J. 8(5), 47-67 (1963) 
Kahn L.F., Dill J.C., Reutlinger C.G.: Transfer and development length of 15-mm strand in high performance concrete girders. J. Struct. Eng. 128(7), 913-921 (2002)

Kose M.M., Burkett, W.R.: Formulation of new development length equation for 0.6 in. prestressing strand. PCI J. 50(5), 96-105 (2005)

Krishnamurthy, D.: Influencia del procedimiento de destesado sobre las tensiones en las zonas de anclaje y sobre la longitud de transmisión, en elementos de hormigón pretensado con armaduras pretesas. Traslation of paper published in The Indian Concrete Journal 44(3). Hormigón y Acero June, 49-65 (1970)

Lane S.N.: A new development length equation for pretensioned strands in bridge beams and piles. Federal Highway Administration. Research FHWA-RD-98-116. Mclean, VA (1998)

Larson, K.H., Peterman, R.J., Esmaeily, A.: Bond characteristics of self-consolidating concrete for prestressed bridge girders. PCI J. 52(4), 44-57 (2007)

Logan, D.R.: Acceptance criteria for bond quality of strand for pretensioned prestressed concrete applications. PCI J. 42(2), 52-90 (1997)

Lu Z., Boothby Th.E., Bakis Ch.E., Nanni A.: Transfer and development lengths of FRP prestressing tendons. PCI J. 45(2), 84-95 (2000)

Mahmoud Z.I., Rizkalla S.H., Zaghloul E.R.: Transfer and development lengths of carbon fiber reinforcement polymers prestressing reinforcing. ACI Struct. J. 96(4), 594-602 (1999)

Martí-Vargas J.R., Serna-Ros P., Fernández-Prada M.A., Miguel-Sosa P.F., Arbeláez C.A.: Test method for determination of the transmission and anchorage lengths in prestressed reinforcement. Mag. Concr. Res. 58(1), 21-29 (2006a)

Martí-Vargas J.R., Arbeláez C.A., Serna-Ros P., Fernández-Prada, M.A., Miguel-Sosa P.F.: Transfer and development lengths of concentrically prestressed concrete. PCI J. 51(5), 74-85 (2006b)

Martí-Vargas J.R., Arbeláez C.A., Serna-Ros P., Navarro-Gregori J., Pallarés-Rubio, L.: Analytical model for transfer length prediction of $13 \mathrm{~mm}$ prestressing strand. Struct. Eng. Mech. 26(2), 211-229 (2007a)

Martí-Vargas J.R., Arbeláez C.A., Serna-Ros P., Castro-Bugallo C.: Reliability of transfer length estimation from strand end slip. ACI Struct. J. 104(4), 487-94 (2007b)

Martí-Vargas J.R., Serna P., Navarro-Gregori J., Bonet J.L.: Effects of concrete composition on transmission length of prestressing strands. Constr. Build. Mater. 27, 350-356 (2012a)

Martí-Vargas, J.R., Caro, L., García-Taengua, E., Serna, P.: Test method to characterize bond creep in pretensioned concrete. In: Cairns, J.W., Metelli, G., Plizzari, G.A. (eds.) Bond in Concrete 2012: Bond, Anchorage, Detailing. Fourth International Symposium, 17th-20th June 2012, Vol. I pp. 387-393. Publisher creations, Brescia, Italy (2012b)

Martí-Vargas J.R, Serna P., Navarro-Gregori J., Pallarés, L.: Bond of $13 \mathrm{~mm}$ prestressing steel strands in pretensioned concrete members. Eng. Struct. 41, 403-412 (2012c)

Marshall, G.: End anchorage and bond stress in prestressed concrete, Mag. Concr. Res. 1, 123-127 (1949)

Mayfield, B., Davies, G., Kong, F.K.: Some tests on the transmission length and ultimate strength of pretensioned concrete beams incorporating Dyform strand. Mag. Concr. Res. 22(73), 219226 (1970)

Mitchell, D., Cook, W.D., Khan, A.A., Tham, Th.: Influence of high strength concrete on transfer and development length of pretensioning strand. PCI J. 38(3), 52-66 (1993)

Nanni, A., Utsunomiya, T., Yonekura, H. and Tanigaki, M.: Transmission of prestressing force to concrete by bonded fiber reinforced plastic tendons. ACI Struct. J. 89(3), 335-344 (1992)

Oh, B.H., Kim, E.S.: Realistic evaluation of transfer lengths in pretensioned, prestressed concrete members. ACI Struct. J. 97(6), 821-830 (2000)

Peterman, R.J.: The effects of as-cast depth and concrete fluidity on strand bond. PCI J. 52(3), 72101 (2007)

Pozolo, A.M., Andrawes, B.: Transfer length in prestressed self-consolidating concrete box and Igirders. ACI Struct. J. 108(3), 341-349 (2011)

Ramirez, J.A., Russell, B.W.: Transfer, development, and splice length for strand/reinforcement in High-Strength Concrete. NCHRP Report 603. National Cooperative Highway Research Program (2008)

Russell, B.W., Burns, N.H.: Measured transfer lengths of 0.5 and 0.6 in. strands in pretensioned concrete. PCI J. 41(5), 44-65 (1996)

RILEM: RPC6 Specification for the Test to Determine the Bond Properties of Prestressing Tendons. Réunion Internationale des Laboratoires et Experts des Matériaux, Systèmes de Constructions et Ouvrages, Bagneux., France (1979)

Roller, J.J., Martin, B.T., Russell, H.G., Bruce, R.N.: Performance of prestressed high strength concrete bridge girders. PCI J. 38(3), 34-45 (1993) 
Shahawy, M., Issa, M., Batchelor, B.: Strand transfer lengths in full scale AASHTO prestressed concrete girders. PCI J. 37(3), 84-96 (1992)

Shing, P.B., Frangopol, D.M., McMullen, M.L., Hutter, W., Cooke, D.E., Leonard, M.A.: Strand development and transfer length tests on high performance concrete box girders. PCI J. 45(5), 96-109 (2000)

Soudki, K., Green, M., Clapp, F.: Transfer length of carbon fiber rods in precast pretensioned concrete beams. PCI J. 42(5), 78-87 (1997)

Staton, B.W., Do, N.H., Ruiz, E.D., Hale, W.M.: Transfer lengths of prestressed beams cast with self-consolidating concrete. PCI J. 54(2), 64-83 (2009)

Swamy, R.N., Anand, K.L.: Losses in transmission length and prestress in high alumina cement concrete, P. I. Civil Eng. 59, 293-307 (1975)

Tabatabai, H., Dickson, Th.: The history of the prestressing strand development length equation. PCI J. 38(5), 64-75 (1993)

Tadros, M.K., Baishya, M.C.: Discussion of A review of strand development length for pretensioned concrete members. PCI J. 41(2), 112-127 (1996)

Trent, J.: Transfer length, development length, flexural strength, and prestress loss evaluation in pretensioned self-consolidating concrete members. MS Thesis, Virginia Polytechnic Institute and State University, Blacksburg, VA (2007)

Weerasekera, I.: Transfer and Flexural Bond in Pretensioned Prestressed Concrete. Dissertation, University of Calgary, UMI Dissertation Services, ISBN 0-315-71095-5 (1991)

William, G.W., Shoukry, S.N., Riad M.Y.: Development of early age shrinkage stresses in reinforced concrete bridge decks, Mech. Time-Depend. Mater. 12, 343-356 (2008)

Zia P., Mostafa T.: Development length of prestressing strands. PCI J. 22(5), 54-65 (1977)

Zou, P.X.V.: Long-term properties and transfer length of fiber-reinforced polymers. J. Compos. Constr. 7(1), 10-19 (2003) 


\section{List of figure captions}

Fig. 1 Schematic prestressing stress diagram in a prestressed member after the prestress transfer

Fig. 2 Transfer length models

Fig. 3 Test equipment layout

Fig. 4 Test procedure stages

Fig. 5 Transfer length determination according to the ECADA+ test method

Fig. 6 General view of the stored specimens

Fig. 7 Initial transfer length determination for the A-80-24 series

Fig. 8 Evolution of prestressing force with time for the A-80-24 series

Fig. 9 Transfer length test results for the A-100-24 (a) and A-80-24 (b) series

Fig. 10 Transfer length variation versus concrete stress level

Fig. 11 Evolution of strand end slip with time for the A-80-24 series

Fig. 12 Computed transfer lengths according to Guyon's expression for the A-100-24 (a) and A80-24 (b) series

Fig. 13 Longitudinal concrete surface strain profiles for specimens A-100-24-1350 (a) and A-8024-1350 (b)

Fig. 14 Proposed model for transfer length 